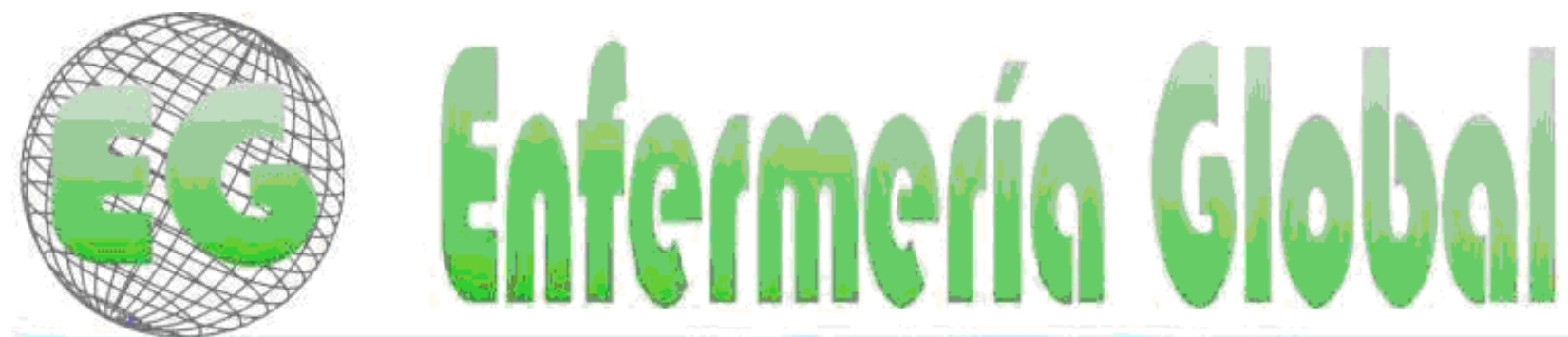

1SSN $1695-6144$

Revista electrónica cuatrimestral de Enfermeria

$\mathrm{N}^{0} 16$

Junio 2009

www.um.es/eglobal/

REFLEXIONES - ENSAYOS

\title{
ESTRATEGIA EDUCATIVA COMO EJE FUNDAMENTAL DEL CUIDADO ENFERMERO HACIA LA GESTANTE QUE VIVE EN CONDICIÓN DE VIH/SIDA, PARA LA PREVENCION DE LA TRANSMISIÓN VERTICAL
}

EDUCATION STRATEGY AS A KEY POINT IN NURSING CARE OF A EXPECTANT MOTHER LIVING WITH HIVIAIDS, FOR THE PREVENTION OF VERTICAL TRANSMISSION

\author{
*Montero, L., " Colmenares, Z., "Reina, R., **Montero, Y. \\ *Magíster en Enfermería. Docente Escuela de Enfermería. Universidad de Carabobo.**ucda. \\ en Enfermería. Venezuela
}

Palabras Claves: Estrategias Educativas, Cuidado Enfermero, Gestante, Virus de Inmunodeficiencia Humana, Transmisión Vertical.

KeyWords: Educational Strategies, Nursing Care, Expectant Mother, Human Immunodeficiency Virus, Vertical Transmission

\section{RESUMEN}

El incremento de VIH SIDA en la población femenina en edad fértil trae como consecuencia la infección vertical de la madre al hijo y a su vez la incidencia del VIH SIDA en la población infantil. En este sentido, la transmisión vertical o prenatal del VIH puede ocurrir durante el embarazo, el parto o por medio de la leche materna en el amamantamiento. En este sentido, se plantea como objetivo diseñar un plan de acción con estrategias educativas como eje fundamental del cuidado enfermero hacia la gestante que vive en condición de $\mathrm{VIH} /$ sida, para la prevención de la transmisión vertical dirigido a las mujeres embarazadas que asisten al centro de atención integral "La Morera", Municipio Juan German Roscio, Guarico - Venezuela.

La metodología utilizada se enmarcó en un proyecto factible fundamentado en un estudio de campo descriptivo, la población estuvo conformada por las usuarias que asisten a la consulta de dicho centro, la muestra de tipo no probabilística censal comprendió 20 gestantes que asistieron durante el período de aplicación del instrumento de recolección de datos, este último correspondió a un cuestionario de 30 preguntas dicotómicas, el cual fue validado por expertos y la confiabilidad obtenida a través de Kuder Richarsond 20, fue de 0,89. 
Los resultados determinan que las usuarias tenían conocimiento general acerca de la transmisión vertical del VIH/SIDA, teniendo limitaciones con respecto a los factores de riesgo; en este sentido, se concluye que el cuidado de enfermería en el área obstétrica juega un papel importantísimo en la detección, prevención y atención de la transmisión vertical del VIH SIDA, siendo, además del control respectivo, las orientaciones que puede recibir por parte del equipo de salud, de allí que cuente con herramientas como los planes de enseñanza, previamente diseñados para lograr llevar a cabo la educación que requieren.

\section{ABSTRACT}

The increase in HIV / AIDS in females of childbearing age results in the vertical infection from mother to child and in turn, the incidence of HIV/AIDS in children. In this regard, prenatal or vertical transmission of HIV can occur during pregnancy, childbirth or through breast milk in breastfeeding. In this sense the objective is to design an action plan with educational strategies as key to nursing care of pregnant women living with HIV / AIDS, for prevention of vertical transmission of expectant mothers at the care center of La Morera, Juan German Roscio, Guarico (Venezuela).

The methodology is part of a feasible project based on a descriptive field study, the population comprising of users attending the consultation of this center. The non-probability sample of the census included 20 expectant women who attended during the implementation period the data collection, which corresponded to a questionnaire of 30 dichotomous questions, and was validated by experts. The reliability obtained by Kuder Richarsond 20 was 0.89 .

The results determined that the patient had general knowledge of vertical transmission of HIV / AIDS, have limitations with respect to risk factors. In this sense, it was concluded that nursing care in obstetrics plays a very important role in detection, prevention and treatment of vertical transmission of HIV / AIDS in addition to the respective control that can receive guidance from the health team. That is the reason why having tools such as lesson plans, designed beforehand to offer the education they require.

\section{INTRODUCCIÓN}

La salud es uno de los aspectos esenciales en el desarrollo de los pueblos. En esta idea la Organización Mundial de la Salud propuso en el año 1978 "Salud para todos en el año 2000" constituyéndose la Atención Primaria en Salud en el eje de la atención sanitaria a nivel mundial, por estar dirigida hacia la prevención de la salud, promoción, y a modificar los estilos de vida, según la condición de vida, por ser esta una de las determinantes de la salud y en consecuencia promocionar la vida para prolongar la existencia. Sin embargo, a pesar de los esfuerzos que hacen los gobiernos por mantener elevados los índices de salud de la población, actualmente se mantiene un repunte de muchas enfermedades consideradas erradicadas, sumándose a ellas el virus de inmunodeficiencia humana, convirtiéndose en azote para la humanidad.

La salud y la calidad de vida son un derecho consagrado en la Constitución de la República Bolivariana de Venezuela, que a su vez orientan todas las acciones de los organismos que conforman el Sistema Público Nacional de Salud y de las personas que de una u otra manera lo integran. Esta direccionalidad estatuye el imperativo ético de responder a las necesidades sociales de todas y cada una de las personas, garantizando así los derechos con universalidad y equidad, a través de la aplicación del pensamiento estratégico para orientar las acciones en salud y garantizar la calidad de vida y de salud y de atención de la población venezolana. 
Sin embargo, aun cuando existen programas que permiten mejorar las coberturas y disminuir las oportunidades perdidas, para dar coherencia a los servicios de salud y direccionalidad en el comportamiento del equipo de salud, porque sus contenidos le muestran las diferentes actividades en los distintos niveles administrativos y de prestación de servicios, se mantiene un impacto negativo en el manejo del VIH/SIDA, evidenciado por el gran número de mujeres seropositivas embarazadas. Por ende, a las enfermeras (os) como miembros del equipo de salud, les urge asegurar que durante su desempeño en el cuidado a la embarazada, se le proporcione un cuidado humano integral, que vaya más allá de un simple contacto con ella en la consulta prenatal.

\section{SITUACIÓN ACTUAL DE LA EPIDEMIA VIH/SIDA.}

Se denomina Sida al acrónimo del síndrome de inmunodeficiencia adquirida que afecta a los humanos infectados por el Virus de Inmunodeficiencia humana. Una persona vive la condición del SIDA cuando su organismo no es capaz de ofrecer respuesta inmune adecuada contra las infecciones debido a la inmunosupresión causada por el virus. Esta condición emerge en el mundo contemporáneo como uno de los más graves problemas de salud pública por no disponerse de una cura definitiva. El VIH/SIDA es una pandemia caracterizada por un grupo específico de enfermedades y condiciones que ocurren cuando las reacciones de inmunidad se suprimen como resultado de la infección por el virus de inmunodeficiencia humana (VIH). Los efectos de $\mathrm{VIH}$ en el organismo permiten que los patógenos ataquen al cuerpo que tiene poca resistencia, todo esto representa la expresión clínica final de la infección por VIH.

El sida, inducido por el VIH, es una deficiencia inmunológica progresiva e irreversible, que tiene por blanco el sistema inmunitario, proporciona la base para la expresión clínica de infecciones oportunistas o tumorales" (1). Por lo tanto, las personas seropositivas deben mantener un alto nivel de bienestar y un estilo de vida saludable, de manera que su sistema inmunológico se mantenga fortalecido y así evitar la presencia de infecciones oportunista que vayan menguando poco a poco sus condiciones físicas y pueda convertirse en un sobreviviente de larga duración

El Programa Conjunto de las Naciones Unidas sobre el Virus de inmunodeficiencia humana y Sida (ONUSIDA) (2), en el año 2003, estimó que para diciembre del año 2000 existían en el mundo más de 40 millones de personas que vivían con esta condición. En la última reunión realizada en España en el año 2002, se concluyó que existían más de 43 millones infectados, señalando que de esa población 16,4 millones correspondían al sexo femenino y una cifra significativa de 1,8 millones de niños, si se considera a estos como futuro de la humanidad. Según datos de la misma organización con respecto a los casos de pediatría, en el año 2001 se infectaron 800.000 niños lo que representó el 16\% de infectados de la población mundial.

Esta última cifra está relacionada con la capacidad que tiene el virus de transmitirse de madre a hijo, lo que se conoce como transmisión vertical; demostrándose que el virus se puede transmitir durante el embarazo, en el momento del parto y a través de la lactancia materna. En este sentido, aun cuando se han difundido orientaciones ante las conductas que representan riesgos para contraer el virus, esfuerzos masivos en investigaciones para encontrar la vacuna y un tratamiento verdaderamente efectivo, todavía se considera una enfermedad mortal porque la fuentes de infección y las vías de transmisión son los factores más importantes para la propagación del Sida, más que el comportamiento biológico del mismo. 
Venezuela no escapa a esta situación, y para el año 1998, según cifras del Centro de Investigaciones Económicas y Sociales, señala que el número de infectados por el Virus de Inmunodeficiencia Adquirida ha ido en aumento y para ese año 63.000 personas eran seropositivas y 9.200 estaban confirmados como casos de SIDA. Asimismo, comentan una marcada tendencia al incremento del número de casos en las edades comprendidas entre 15 y 24 años, con marcada cifra de mujeres en edad reproductiva. (3).

Los datos expuestos anteriormente evidencian que la transmisión vertical es el modo dominante de la infección por VIH en la población infantil, la vulnerabilidad del grupo infantil está relacionada también con otros aspectos, tales como: el incremento en la tasa de infección por el virus de inmunodeficiencia humana en mujeres en edad reproductiva, la carencia de programas de tamizaje para VIH en mujeres gestantes y su repercusión sobre el feto o accesos a intervenciones terapéuticas a las mujeres seropositivas. Estos datos justifican por qué la transmisión vertical se ha convertido en este momento en el centro para la prevención del Virus de inmunodeficiencia humana.

La misma organización indica que un $25 \%$ de los bebés que nacen de madres seropositivas desarrollan la infección del VIH. Muchos de estos niños fallecen antes de llegar al año o a los dos años de edad y, aunque algunos viven por años, su desarrollo se atrasa acompañado de infecciones oportunistas recurrentes, (4). Las madres embarazadas y seropositivas deben recibir tratamientos antirretrovirales para evitar que el virus se transmita a sus futuros hijos e hijas. Actualmente se dispone de mayor capacidad para admitir más mujeres embarazadas en los programas antirretovirales y reducir el riesgo de transmisión en un $90 \%$; ya que esta transmisión es prevenible si se detecta tempranamente en la madre la presencia del virus y si la madre y el recién nacido son sometidos oportunamente a tratamiento con drogas antirretovirales y suspendiendo el amamantamiento. Por ello se considera necesario poner en marcha medidas para reducir las tasas de la transmisión vertical, como lo es la puesta en práctica de estrategias educativas.

\section{VIH/SIDA Y LA GESTACIÓN}

La transmisión del VIH/SIDA se da por vía sexual, parenteral y perinatal”. (5). Las formas de transmisión del VIH determinan las características epidemiológicas del sida e incluyen el contacto sexual, heterosexual, tanto en parejas masculinas como en parejas heterosexuales, la inoculación de sangre o productos sanguíneos, en los consumidores de drogas endovenosas y la transmisión de la madre al hijo, bien sea en el útero, durante el nacimiento y la lactancia materna (6).

En la medida en que la infección por VIH se traslada cada vez más a la población femenina, así mismo, va en aumento el número de casos de mujeres seropositivas embarazadas y en consecuencia el incremento de casos de niños y niñas infectados. Teniendo como consecuencia la trasmisión vertical del virus, es decir, la transferencia de la infección materna a su descendencia durante la gestación, durante el trabajo de parto y la transmisión post-parto a través de la lactancia materna. (7).

La transmisión vertical del VIH/SIDA es considerada como una vía relevante en la adquisición de la infección, por lo que las razones anteriormente expuestas hacen necesario el promover en la embarazada un control prenatal precoz, debido a que puede ser incorporada más tempranamente a la profilaxis antirretoviral, una evaluación integral y seguimiento periódico para evaluar su estado clínico, inmunológico y virológico, además de la vigilancia de los efectos colaterales de las drogas antivirales. Sobre esta base se pudiese 
evitar la infección por medio de la transmisión vertical, ya que actualmente las vías de transmisión de la infección por este medio son reconocidas.

En este marco, es de vital importancia la identificación temprana del VIH y los factores de riesgo en la mujer embarazada, por los promotores del cuidado de la salud porque permite poner en práctica estrategias educativas que ayuden a la prevención de la infección, aportando los conocimientos necesarios que pudiesen llevar a las madres infectadas a comprender y equilibrar el potencial de transmisión y así puedan tomar decisiones conscientes e informadas acerca de los posibles riesgos a que están expuestas ellas y sus futuros hijos o hijas por nacer..

Durante el período de gestación la embarazada seropositiva o que vive con sida está sometida a riesgo permanente, porque su organismo tiene que adaptarse a los cambios fisiológicos y psicológicos propios del embarazo, aunado a ello presenta una disminución de las cifras de linfocitos CD4 aumentando la probabilidad de presentar infecciones oportunistas, las gestantes infectadas por el $\mathrm{VIH}$ suelen presentar mayor numero de complicaciones obstétricas, retraso de crecimiento intrauterino, prematuridad, carioamnionitis y endometritis post parto(8). Queda implícita la idea de que la probabilidad de consecuencias adversas aumenta por la presencia de una o más características 0 factores determinantes de estas circunstancias. En consecuencia, las enfermeras y enfermeros orientaran su comportamiento a la identificación de riesgos definidos, como es la carga viral e inmunológica para realizar intervenciones enfermeras independientes y modificarlas para evitar daños a la salud de la embarazada.

Con respecto a la carga viral materna, definida como la cantidad del VIH presente en la sangre de una persona, que permite la replicación del virus del VIH (9). Pues, las personas con una alta carga viral son más propensas a desarrollar el SIDA y en el caso de la gestante, los estudios demuestran que existe una clara correlación entre el nivel de carga viral materna y el riesgo de infectar a su bebé. Sin embargo, actualmente se carece de evidencias que demuestren un nivel de carga viral por encima del cual la transmisión sea del $100 \%$ y en consecuencia los estudios realizados no aseguran un umbral de carga viral por debajo del cual se garantice la ausencia de transmisión.

Así pues, todavía no se ha establecido ningún valor de carga viral que discrimine entre transmisión vertical y ausencia de transmisión vertical. Esto viene a demostrar la importancia del tratamiento antirretroviral incluso en madres con cargas virales plasmáticas bajas. Por estas razones, las enfermeras y enfermeros deben interpretar los resultados de la carga vírica de la madre en la consulta prenatal, con el propósito de inducirla al inicio de la terapia farmacológica y ayudarla a desarrollar la habilidad de tomar las medicinas como han sido prescritas.

Por otra parte, tomando en cuenta que la carga vírica es el factor más importante en determinar si los medicamentos están funcionando o no, se debe estar vigilante de la determinación de la carga vírica de la embarazada cada dos o cuatro semanas para individualizar y optimizar el tratamiento. Sin embargo, existen otros elementos predisponentes a la infección, distintos a la carga vírica materna, como son: los factores virales, los placentarios aunque no están establecidos los mecanismos por los cuales el virus pueda atravesar la barrera útero placentaria, a medida que avanza la gestación, la capa interna del citotrofoblasto placentario se va haciendo más fina, aumentando la susceptibilidad a la infección intrautero; fetales y neonatales, obstétricos y tipos de parto y los asociados a la lactancia materna. (10). 
Queda demostrado que al producirse una alteración de la integridad placentaria el embrión o feto está expuesto a infecciones, así las madres con recuento bajo de linfocitos CD4 tienen un riesgo superior de transmitir la infección. En cuanto a los factores neonatales y fetales, se puede decir ya que la edad gestacional al momento de la exposición es un factor íntimamente relacionado con la transmisión, ya que la prematuridad determina un mayor riesgo de infección. Así mismo la integridad de la piel esta ligada a la edad gestacional y al peso del recién nacido, los recién nacidos de bajo peso para la edad gestacional tienen un mayor riesgo de infección por el VIH durante el periodo gestacional. (11).

Es por ello que los procedimientos invasivos considerados como factores obstétricos en la transmisión vertical durante el parto representan un mayor riesgo de infección para el feto, razón de su contraindicación. De forma que la ruptura prematura de membrana facilita el contacto del feto con la sangre y las secreciones cervicovaginales, representando un riesgo, independientemente del tipo de parto, ya que cada hora que transcurra de la ruptura prematura de las membranas se incrementa en un dos por ciento la tasa de transmisión. Es decir, una madre seropositiva tiene más probabilidad de transmitir la infección a su hijo si la bolsa de agua se rompe cuatro horas antes del parto, es por eso la necesidad de abordar el nacimiento mediante la cesárea programada.

La cesárea programada, es la realizada antes del inicio del trabajo de parto, estudios recientes han puesto de relieve el papel protector de la cesárea, por estas razones la cesárea electiva o programada en las gestaciones a término es considerada una intervención de profilaxis en la transmisión vertical. En esta situación la enfermera al realizar la valoración a la gestante debe reconocer este factor de riesgo para dar cuidados peri operatorios inmediatos, evitar el tiempo de exposición y la posible infección del feto por esta vía. (12)

Cabe destacar que el VIH se transmite a través de la leche materna por lo que en las madres infectadas está contraindicada la lactancia materna (8). Esta situación ha generado temor a las comunidades mundiales, en tanto que la misma aporta al niño y niña la protección inmunológica necesaria para garantizar el inicio de una vida sana durante los primeros años de su ciclo vital. Estudios recientes demuestran que el nivel y la duración de la viremia en la leche materna, los mecanismos protectores de la infección viral, la inmunidad específica local frente al VIH y un tiempo de amamantamiento mas allá de tres meses y en especial más de seis meses se convierte en un riesgo adicional de infección para el neonato producto de una madre seropositiva. En este marco, se evidencia una controversia considerando los beneficios de la lactancia materna y las consecuencias de amamantamiento en una embarazada seropositiva de acuerdo a estudios realizados. Bajo estas circunstancias el papel de la enfermera consiste en ayudar a la madre a que decida o no, optar por la lactancia materna, brindando alternativas de alimentación del recién nacido, asegurando además que la madre portadora de la infección, no sea discriminada o acusada de poner en riesgo a su hijo o hija a contraer VIH.

Bajo esta circunstancia, si la madre seropositiva decide no amamantar a su niño o niña, la enfermera y enfermero le enseñará a preparar las cantidades adecuadas de alimentos alternativos de manera segura, para minimizar los riesgos en la salud propios de esa edad. Asimismo, si la madre decide amamantar, apoyarla en su elección y aportarle la información necesaria sobre la opción de suspender la lactancia materna en cuanto esté en condiciones de proveer alimentación alternativa adecuada.

Evidentemente toda mujer seropositiva al VIH se considera prioridad en el control prenatal, por la consulta de alto riesgo obstétrico una vez diagnosticada su seropositividad para 
incluirla en el protocolo de tratamiento antirretoviral. Este se inicia después del primer trimestre; por desconocimiento de los efectos potenciales de estas drogas sobre el feto, durante la organogénesis. En esta perspectiva el médico informara a la gestante acerca de los riesgos conocidos y potenciales que repercutirán en la salud fetal y del recién nacido. En consecuencia, la enfermera(o) seguirá dando prioridad a la embarazada reafirmándole la adherencia al tratamiento, que consiste específicamente en la administración de drogas antirretovirales a la mujer en el periodo de gestación para mantener la salud de ella y el feto en un estado óptimo y luego al recién nacido durante sus primeras seis semanas de vida. En presencia de cualquier factor de riesgo, mantener las indicaciones, asistiendo inmediatamente a la consulta.

El tratamiento antirretoviral sirve para interrumpir o inhibir uno de los pasos que $\mathrm{VIH}$ necesita para lograr su reproducción dentro de las células del sistema inmunológico(13), sin embargo es necesario tener claro que los medicamentos antirretrovirales no curan la infección; sin embargo ayudan a mantener a la persona en buenas condiciones de salud y productivo, porque retrasan la progresión clínica y aumentan significativamente la supervivencia debido a la capacidad de recuperar el sistema inmunológico. Esto explica por qué la meta de embarazada al igual que la enfermera(o) de la consulta es lograr la interrupción de la replicación del VIH en su organismo.

De ahí, pues, que conociendo lo significativo de este momento en las gestantes, es necesario informar el uso correcto de los medicamentos por parte de la enfermera, la importancia del cumplimiento del esquema de tratamiento, y otros aspectos relacionados, como son los efectos colaterales asociados con el uso de las drogas como son los problemas gastrointestinales, vómito y diarrea. Por otro lado los problemas hematológicos con más frecuencia la anemia, leucopenia y trombocitopenia.

Por consiguiente la enfermera(o) durante la consulta prenatal tomará en cuenta permanentemente las recomendaciones para la vigilancia de los efectos colaterales y el apego que debe mostrar la embarazada de respetar fielmente el horario de la toma de los medicamentos prescritos, incluyendo los horarios y los cambios alimenticios a seguir. Sin embargo, la terapia antirretroviral es demasiado compleja, y los resultados varían de una persona a otra. En este sentido, la enfermera en la consulta debe ser una experta y orientar a la embarazada para que se sienta cómoda con el médico tratante. Sugerirle escribir las dudas y las preguntas y llevarlas a su cita con el médico; ayudándola a recordar todo lo que debe saber acerca de los beneficios y riesgos del tratamiento. En este orden de ideas debe convencerla de su disposición para empezar y seguir el tratamiento como ha sido prescrito.

Finalmente, explicarle que los medicamentos disminuyen la carga vírica y cuando no se administran correctamente, se expone a una replicación del virus a mayor velocidad evitando que el tratamiento cumpla su cometido y aumentando la resistencia farmacológica del virus; dejándola con menos opciones ante las oportunidades de tratamiento. En la actualidad se dispone de diferentes esquemas de tratamiento con la intención de disminuir las tasas de transmisión vertical a nivel mundial. El mismo es adaptado a cada país de acuerdo a los recursos monetarios disponibles, considerando los altos costos del tratamiento.

De igual forma, el tratamiento antirretroviral no diferirá de la mujer no embarazada, las indicaciones se harán de acuerdo a los diferentes escenarios, tomando en cuenta los efectos teratógenos, la edad del embarazo y las combinaciones potencialmente tóxicas ya que el embarazo no ha de limitar la escogencia de las drogas antirretrovirales. Actualmente el protocolo de más uso es el recomendado por el CDC de Atlanta (14) de acuerdo a los 
diferentes escenarios, a saber: embarazadas infectadas con VIH sin terapias previas, embarazadas con $\mathrm{VIH}$ que reciben terapia antirretroviral durante el embarazo, mujer embrazada con VIH que no recibió terapia antirretroviral durante el embarazo y acude en trabajo de parto; asimismo recién nacidos de madres infectadas que no recibieron terapia durante el embarazo.

En este orden de ideas, en el Centro objeto de estudio se dan todos los escenarios. En el caso de la embarazada infectada sin terapia antirretroviral previa se inicia profilaxis antirretroviral después del primer trimestre, incluyendo la zidovudina, discutiendo los riesgos beneficios con la embarazada. Asimismo en la infectada que recibe terapia antirretroviral y acude después del primer trimestre continuar tratamiento. Si recibe el esquema terapéutico permitido continuarlo y omitir las drogas con probables efectos teratógenos, discutiendo los riesgos beneficios si acude en el primer trimestre del embarazo. De la misma manera si acude en el inicio del primer trimestre del embarazo suspender todas las drogas y reiniciar el tratamiento en la semana catorce de gestación.

En esta perspectiva también se recomienda el uso del Protocolo PACTG 076 (15), debido a que su aplicación ha demostrado una disminución en la tasa de transmisión vertical de un $25 \%$ a un $8 \%$, utilizando la Zidovudina endovenosa antes del parto, intraparto y en el recién nacido independientemente de los niveles de la carga vírica materna. En este país actualmente la droga de primera elección es la Zidovudina asociada con otras drogas antirretrovirales para los casos de las embarazadas seropositivas; que consiste en la administración de Zidovudina por vía oral, desde la semana 14 de gestación hasta el inicio del trabajo de parto.

Una vez pautada la cesárea a la semana 38 de gestación, tres horas antes del inicio de la intervención se administrará zidovudina, cuya dosificación corresponde a 2 mgs/ kg/peso, a pasar en una hora por vía endovenosa y luego dosis de $1 \mathrm{mg} / \mathrm{kg} /$ hora en infusión continua hasta el pinzamiento del cordón. En cuanto al recién nacido, se evitarán procedimientos invasivos y será evaluado inmediatamente por el neonatólogo, quien omitirá la lactancia materna con consentimiento informado e indicará iniciar tratamiento con Zidovudina seis a ocho horas después del nacimiento, durante seis semanas y la dosificación está relacionada con la edad gestacional.

En este marco de referencia, para los recién a término la dosificación corresponde a 2 $\mathrm{mgs} / \mathrm{kg} /$ dosis cada seis horas. Por otro lado los recién nacidos pretérmino, $2 \mathrm{mgs} / \mathrm{kg} / \mathrm{dosis}$ cada doce horas. Además continuar con la indicación cada ocho horas después de la segunda semana en neonatos de treinta semanas de edad gestacional o a la cuarta semana en neonatos de menos de treinta semanas de edad gestacional. De igual manera iniciar en la sexta semana del nacimiento Trimetropin Sulfa a dosis de $150 \mathrm{mg} / \mathrm{m} 2 \mathrm{SC}$ tres veces a la semana hasta descartar en él la infección por $\mathrm{VIH}$ e incluirlo en la consulta del pediatra infectólogo, quien será el responsable de atender a los niños de las embarazadas seropositivas.

Es fundamental, en la persona enfermera que cuida a la embarazada seropositiva convertirse en una experta en comunicaron terapéutica, por cuanto que su actitud está encaminada al cuidado significativo de dos personas, restableciendo o conservando el estado inmunológico a través del tratamiento y seguimiento de la madre. Ayudando a la embarazada a incrementar los niveles de calidad vida de la madre y el embrión o feto y así intentar disminuir las tasas de morbi-mortalidad por causa del VIH/SIDA. 


\section{ESTRATEGIAS EDUCATIVAS}

Uno de los pilares filosóficos de la profesión de enfermería radica en impartir educación al ser a quien le proporciona cuidado, con el propósito de orientarlos hacia conductas protectoras de salud; en consecuencia mejorar la calidad de vida, ayudando a que la persona cuidada desarrolle su capacidad de vivir o esforzarse en compensar la alteración de las funciones lesionadas por la enfermedad, buscando la forma de suplir la disminución física, afectiva y social que conlleva la misma. Por lo antes expuesto es la persona enfermera(o) quien puede impactar en la formación y educación de la mujer embarazada promoviendo el cuidado de la salud como eje fundamental y así contribuir a establecer conductas de autocuidado.

Porque el cuidado retiene una dimensión esencial del trabajo profesional en especial al lidiar con crisis de la vida y problemas del mantenimiento de la salud, además de ser un proceso terapéutico de relación interpersonal; es decir, va a trascender en un proceso de interacción humana, para establecer una interconexión de forma tal que permita el acceso al espíritu humano de la embrazada, reconociéndola como persona, sujeta a dignidad y derechos, acorde a su naturaleza. Elevando así su conciencia para que ésta asuma el aprendizaje como estrategia para fortalecer su situación de salud y pueda traer al mundo un ser humano sano independientemente de su afección.

El cuidado es importante para mantener la alianza social, proveer sistemas de apoyo psicológicos y de traer normas culturales de satisfacción. Así, el cuidado enfermero entraña una práctica sustentada en la antropología filosófica y la ética, como base humanística del desempeño que le sirve para la reflexión y la argumentación de sus acciones y comprender que la esencia de enfermería es el cuidar y bajo este enfoque asumir el cuidado de la embrazada seropositiva como un compromiso ético y moral; con conciencia inmerso en su función social; evidenciado en el respeto a su dignidad, una comprensión empática, la compasión y un respeto cálido. Es decir, es en la conexión con la embarazada a través de sus valores, donde la intencionalidad marca la diferencia y donde la conciencia transciende lo físico como objetivo del cuidado.

En resumen la intencionalidad y la conciencia serán los núcleos de trabajo, porque amplía las posibilidades, ayudando a despertar lo científico y lo ético potencializando los resultados de la curación en el cuidado. El cuidado es un factor vital para el crecimiento humano, mantenimiento de la salud y la sobrevivencia, ya que cuidar es un acto de vida que tiene por objetivo, en primer lugar y por encima de todo, permitir que la vida continúe y se desarrolle, (16). Esta necesidad de asegurar el mantenimiento de la vida da lugar a un conjunto de actividades indispensables de las que se hacen cargo las enfermeras y enfermeros.

Por estas razones, al realizar la practica profesional se debe considerar que la esencia del cuidado de enfermería está en cuidar, promover la salud, prevenir la enfermedad y contribuir a una vida digna de las personas (17), todo esto mediante la promoción de la salud, dirigida a alcanzar un alto nivel de bienestar, a través de los procesos que propician la modificación de los hábitos personales(18). Es decir, proporcionar a las personas los medios necesarios para mejorar su estilo de vida, en consecuencia su salud y ejercer un mayor control sobre la misma.

De tal manera que se debe valorar y abrazar las prácticas del cuidado y experiencias que constituyen la parte importante de la práctica enfermera. En otras palabras una persona enfermera(o) comprometida con el cuidado; donde la prioridad sea la mujer gestante que vive en condición de seropositiva, tratándola de forma amorosa y humana y reconociendo el 
beneficio terapéutico del cuidado para iniciar la educación en salud. Porque actualmente se evidencian una serie de cambios en la percepción de la salud y en la organización de los cuidados que hacen que esa educación sea todavía más valiosa. La enfermera(o) trata de descubrir e interpretar nuevos hechos, porque tiene como meta el aumentar el saber y los conocimientos; por cuanto, la gestante con infección en HIV tiene derecho a saber y a ser informada del diagnóstico, el pronóstico, tratamiento y los riesgos de su patología y a este respecto tomar decisiones inteligentes e informadas sobre su salud y estilo de vida, aumentando las posibilidades de protección y sobrevivencia para ambos, madre e hijo(a).

Así la enfermera(o) durante el cuidado a la embarazada seropositiva, el primer paso que debe realizar es la identificación de las necesidades de información acerca de los factores de riesgo, educación del bienestar y prevención de las enfermedades. Para esto, debe poner en marcha múltiples intervenciones de cuidado que correspondan a la complejidad de los factores que pudieran estar afectando a la gestante e ir más allá de la intervención enfermera individual, subrayando las estrategias de bienestar que enseñan a las embarazadas a cuidarse de manera sana y aumentar la capacidad de calidad de vida. Por consiguiente utilizará el proceso enfermero como método para organizar sus actividades educativas, porque le permite diagnosticar las respuestas humanas ante las experiencias de salud y enfermedad. Además le proporciona una estructura creativa organizada y un entorno para la aplicación de los cuidados; de igual manera permite identificar las necesidades de cuidado, establecer objetivos y los resultados esperados, establecer y comunicar un plan de cuidado centrado en la persona, proporcionar intervenciones adecuadas y finalmente evaluar la eficacia del cuidado enfermero.

Considerando lo antes planteado utilizará la filosofía en que se basa la educación y una vez reconocida sus capacidades y potencialidades iniciará las actividades de aprendizaje; que en el caso de la embarazada que vive bajo la condición de $\mathrm{VIH}$, las intervenciones de promoción estarían enmarcada en la consejería sobre su situación de salud, nutrición, en el bienestar, a cuidarse de si misma de manera saludable para alcanzar estados de salud más estables, el control del estrés y la autorresponsabilidad. De igual forma se le explicarán de forma sencilla los riesgos de transmisión vertical, la importancia de iniciar la profilaxis antirretroviral para evitar la infección en el recién nacido, aumentando así la posibilidad de mantener un feto sano durante el embarazo y por ende un recién nacido sano. Para esto es necesaria la incorporación de la pareja y del grupo familiar, fortaleciendo el vínculo familiar para repartir las fuerzas relativas y superar las debilidades.

Este aprendizaje estará fundamentado en ciertos postulados filosóficos esenciales para su desarrollo, teniendo como finalidad ayudar a las personas a adquirir los medios que le permitan llegar a ser responsables de su propio bienestar, realizando actividades para la transformación de conceptos, el modo de pensar y bases de la realidad generando en el proceso compromiso, es decir, que cuando la educación es parte del plan de cuidado empieza el proceso educativo. La conducción de este proceso educativo debe estar orientado por un modelo andragógico y sus principios, basado en saber qué saber, cómo y saber hacer, donde la intención es la formación del hombre para la vida. Este proceso se conjuga con el proceso instructivo, es decir, la formación del hombre para vivir y el desarrollo sus potencialidades.

Evidentemente la enfermera(o) en el programa de atención materna debe considerar estos aspectos por cuanto debe despertar en la mujer embarazada portadora del virus de inmunodeficiencia, las potencialidades que le permitan manejar su estado inmunológico para evitar que la infección afecte al embrión o feto y la evolución del embarazo, llegando a la obtención de un niño o niña sana para el resto de su vida. Por lo que la persona enfermera 
debe colocar en primer lugar el aprendizaje del autocuidado de la gestante, como actividad necesaria para que la embarazada obtenga la información y la enseñanza que guíen su el aprendizaje; esto supone un tipo especial de relación con la persona cuidada, donde la comunicación funcional y la relación de ayuda deben estar estrechamente relacionadas para darle un sentido propio al aprender y lo que se aprende, visto el aprendizaje como la adquisición intencionada de nuevos conocimientos, actitudes, conductas y habilidades.

Por lo antes expuesto, la enfermera(o) realizará la recolección de datos que le permitirán reconocer la necesidad de conocimientos de la gestante, si debe aprender nuevas habilidades o cambiar actitudes existentes, asimismo sus capacidades, limitaciones y los factores que puedan influir en su aprendizaje. Esta exige habilidades para la observación y la entrevista, ya que los elementos antes citados son condición necesaria para diseñar el programa educativo.

Este aprendizaje debe centrarse en las necesidades de aprender de la gestante, la buena voluntad y la aptitud para aprender. Este proceso debe desarrollarse en un clima de respeto, de aceptación, de compresión, porque el aprendizaje tiene lugar en tres esferas: en la cognitiva, la afectiva y la psicomotora y cualquier cuestión que quiera aprenderse puede incluir una o todas las esferas. En el caso de la embarazada seropositiva la esfera afectiva es importante porque ella debe crecer como ser humano que se respeta a sí misma y a los otros, con conciencia social y ecológica, de modo que pueda actuar con responsabilidad para hacer lo propio y mantener un estilo de vida más saludable.

Comprender cada esfera prepara a la enfermera para comprender las técnicas de aprendizaje adecuadas. Sin embargo, también debe ser capaz de aplicar los principios básicos, entre ellos tenemos: la motivación, la capacidad para aprender y el entorno del aprendizaje. También depende de los atributos físicos y cognitivos, el grado de desarrollo, el bienestar físico y los procesos del pensamiento. De igual manera, la forma de comunicarse la enfermera(o) y la claridad de sus palabras también se convierten en elementos claves en el aprendizaje y, en consecuencia, el proceso educativo será efectivo, porque la actitud de la persona que enseña influencia el aprendizaje. Entonces iniciará interacciones constructivas y así, va interviniendo cooperativamente y socialmente en el contexto sociocultural, cumpliendo su función social.

En base a lo antes señalado, se puede deducir que esta herramienta ayudará a la modificación de la conducta de la embarazada para promocionar y proteger tanto su salud individual como la de su hijo o hija por nacer. Usar adecuadamente los servicios disponibles y favorecer el desarrollo de la personalidad y formación de nuevos hábitos, así como acercarla a soluciones conscientes mediante un proceso reflexivo para prevenir la transmisión vertical durante el embarazo. En otras palabras, la enfermera(o) cuando planea el aprendizaje de la embarazada señala las acciones a seguir para que adquiera conocimientos amplios y estructurados con la finalidad de manejar con competencia adquirir la nueva situación y evitar la transmisión vertical, determinando las intervenciones que estimularán el aprendizaje y los cambios positivos.

Para impartir la enseñanza se debe valorar el conocimiento del sujeto, así como su nivel cultural y de aprendizaje. La enfermera(o) antes de proceder a la enseñanza realiza una recogida de datos con el fin de detectar las necesidades de información de la embarazada 0 cuáles son los factores que pueden influir en el aprendizaje (19). En la puesta en práctica de estrategias educativas las enfermeras(os) juegan un papel preponderante ya que el ejercicio profesional está encaminado al cuidado de la salud de las personas, tomando en cuenta la promoción de la salud, la prevención de la enfermedad, la participación en el tratamiento e incluyendo la readaptación de las personas a la circunstancia de la situación de salud donde 
se encuentre. En este sentido debe apoyar a la embarazada seropositiva a aceptar su situación de salud, ayudándola a ver más clara sus propias necesidades, brindándole serenidad y apoyándole en la toma de decisiones

Entre las conclusiones reflejan la puesta en práctica de las estrategias educativas a las gestantes que viven en condición de VIH/SIDA, Dada la ausencia de vacunas y la incapacidad actual de la ciencia médica para controlar el virus del SIDA, la educación constituye una de las vías más eficientes para combatir la epidemia. Existe unanimidad en reconocer que la educación tiene un papel clave que cumplir en la prevención, no únicamente para transmitir la información, sino también en el cambio de actitudes y comportamientos relativos al SIDA, tanto como enfermedad que como fenómeno social. En este orden de ideas, los programas sostenidos de prevención del VIH han desempeñado un papel fundamental en la reducción de la cantidad de nuevas infecciones con el VIH. El objetivo principal de los mismos es que las estrategias y materiales pedagógicos estén disponibles hacia las comunidades, donde las enfermeras y enfermeros juegan un papel preponderante, ya que al brindar cuidados estos tienen la capacidad de adaptarse a contextos socioculturales específicos, relacionando los conocimientos, valores, actitudes, competencias, comportamientos de la persona humana a quien le brinda su cuidado.

Por todo lo anteriormente expuesto se recomienda a las Enfermeras que proporcionan cuidado a la mujer en edad reproductiva, y a las gestantes: mantenerse actualizado con respecto a los avances que sobre el VIH/SIDA se generan en función de medidas de transmisión y prevención, integrar a su práctica diaria la educación para la salud, promoviendo el bienestar de las gestantes, concienciar la necesidad de las usuarias de ser orientadas acerca de todo lo referente al tratamiento, respetando su derecho a ser informada. En relación a las Usuarias que viven en la condición de VIH/SIDA, aplicar las medidas preventivas de transmisión vertical del VIH/SIDA, asistir a los talleres que se dictan en el Centro de Atención, con la finalidad de estar informadas acerca de la enfermedad y su tratamiento, Concienciarlas sobre la importancia de traer al mundo niños y niñas sanos.

\section{REFERENCIAS BIBLIOGRÁFICAS}

1- Zelasko, H. (1992) Symposium Interventions in Perinatal Transmission. VI Conference on Retroviruses and Opportunistic Infections; January 1992, Chicago.Session 8.

2- ONUSIDA (2003). Estadísticas sobre el SIDA. Informe del Programa sobre el SIDA.

3- Centro de Investigación Económicas y Sociales (1998) Epidemiología. Departamento de Registros. Caracas, Venezuela.

4- Organización Mundial de la Salud (2000). Vigilancia epidemiológica del sida. Informe Semestral no1, año 2000. Disponible en http/www.msc/es/sida/epidemiologia/actual.

5- Merson, H. (1993) Evolución de la infección del VIH -1 por transmisión vertical en España (1993-1999). IX Congreso de la Sociedad Española de Enfermedades Infecciosas y Microbiología Clínica. Santiago de Compostela, 21-24 de mayo de 1993. Abstract 407.

6- Del Río Solessi, A. (1995) La epidemia del VIH/SIDA y la mujer en México. Salud Pública en México, Vol. 37, № 6.

7- Delgado, A. (2000) SIDA infantil en pediatría. Volumen 12. Editorial España Bilbao.

8- Coll, G. y Martínez (1998). Estimación de de la prevalencia de infección VIH en la embarazada, efectividad de la ZDV en la prevención de la transmisión vertical. Medicina Clínica, Barcelona, España.

9- Holodny, M. y Kuritzkes, V. (1996) Modelo de prevención primaria de las enfermedades de transmisión sexual y del $\mathrm{VIH} /$ sida en adolescentes. 
10- Sociedad Española de Ginecología y Obstetricia (2001) Cesárea y riesgo de transmisión vertical de la infección $\mathrm{VIH}-1$. The Lancet (ed. esp.); España.

11- Guerra, M. y Colb. (2001). Preliminary efficacy, safety, tolerability and pharmacokinetics of short course regimens of nucleoside analogues for the prevention of mother to child transmisión (MTCT) of HIV. Program and abstracts of the XIII International AIDS Conference; July 2000; Durban, South Africa.

12- Fortuna, K. (1998) Intrapartum and neonatal single dose nevirapine compared with zidovudine for prevention of mother-to-child transmission of HIV-1 in Kampala, Uganda.

13- Nieves, V. (2006) Transmisión vertical del VIH-1.¿Hasta donde se puede reducir? Medicina Clínica, Barcelona, España.

14- CDC de Atlanta (2005). VIH/SIDA. [Documento en línea] Disponible: http://www.biocab.org/vih-sida.htm .

15- Connor E (1994) Reduction of maternal-infant transmission of human immunodeficiency virus type with zidovudine treatment. Pediatric AIDS Clinical Trials Group Protocol 076 Study Group. N Engl J Med. s/l.

16- Colliere, F. (1993). Promover la vida. Madrid. Interamericana McGraw-Hill.

17- Ley del Ejercicio del Profesional de Enfermería (2005) Asamblea Nacional Constituyente. Biblioteca Electrónica. Trascripción en línea. Disponible en: http://www.ilustrados.com/publicaciones/EEkkAAluulpXgbWERx.php.

18- Pepper, L. (1999) Bases conceptuales de la enfermería. Paltex, España.

19- Cooper, J. (1999) Estrategias de enseñanza. Guía para una mejor enseñanza. México: Limusa Noriega Editora. 